Background Ultrasound examination (US) of the small joints of the hands and feet in rheumatoid arthritis (RA) has the potential to become a rheumatological bedside procedure to assess early joint pathology. There is a growing number of studies and possible practical applications of US in this field. However, US has not been sufficiently validated with respect to common and early joint manifestations of RA.

Objectives To evaluate the interobserver agreement of ultrasound examination in assessment of finger and toe joints in rheumatoid arthritis.

Methods B-mode and power Doppler US was performed on 150 small joints of 30 patients with active RA (ACR 1987 criteria). Nineteen patients had a disease duration of 2 years or more and eleven patients had a disease duration of less than 2 years. Sixtyone of the joints were clinically active (tender and/or swollen), as evaluated by an experienced rheumatologist. US was performed with a LOGIQ GE 500 unit by means of a 7-13 MHz linear array transducer. In each patient, five preselected small joints were examined: 2nd and 3rd metacarpophalangeal joints, 2nd proximal interphalangeal joint, 1 st and 2nd metatarsophalangeal joints. The number and location of bone erosions, synovial thickening, joint effusion and power Doppler signal in these joints were evaluated and classified on four-grade semi-quantitative scales. Both US examinations were performed independently on the same day by two observers - a radiologist with expertise in musculoskeletal US and a rheumatologist trained in US evaluation of small joints of the extremities. The observers reached consensus as to the evaluation scale prior to the beginning of the study.

Results In the examined joints, exact agreement between the two observers was seen in $84 \%$ of the examinations with regard to bone erosions, in $78 \%$ as to synovitis, in $84 \%$ as to joint effusions and in $82 \%$ as to power Doppler signal assessments. A difference of more than one grade on the evaluation was found in 6, 11, 1 and 3\%, respectively. Corresponding unweighted kappa values were $0.69,0.63,0.63$ and 0.51 .

Conclusion The present study showed a good degree of interobserver agreement for the examined parameters. Our results suggest that ultrasound examination is a reproducible method for assessment of RA joint pathology of the finger and toe joints.

\section{SAT0212 BONE AND JOINT SCAN AS COMPARED TO JOINT CLINICAL EVIDENCE}

C Venditti, R Peluso, M Cimmino, R De Luca Bossa, G Loi, A Spanò, A Del Puente, P Oriente. Rheumatology Unit, University of Neaples "Federico II", Neaples, Italy

\subsection{6/annrheumdis-2001.709}

Background Bone and joint scan using $99 \mathrm{mTc}-\mathrm{MDP}$ is often used in rheumatologic practice, but there is little data on its effective relevance in evaluating chronic articular inflammatory diseases.

Objectives The aim of this work has been to compare bone scan results against clinical evidence of joint inflammatory involvement, evaluating with both approaches the number of affected joints (NAJ) in a group of patients with rheumatoid arthritis (RA) or osteoarthritis (OA).

Methods Bone scan was carried out in 75 consecutive patients (44 RA, $31 \mathrm{OA})$. The nuclear medicine specialist indicated in the report the list of joints showing uptake. In the same patients (without knowing the results of scintigraphy) a rheumatologist diagnosed the NAJ on the basis of clinical signs of inflammation.
Then the patients were stratified in $2 * 2$ tables according to the prevalence of clinical evidence or scintigraphic uptake.

Results The distribution was found to be not significant (chisquare $=1.6, \mathrm{p}=0.2$ ). The percentage of patients without uptake was only $5.3 \%$. In 33 patients (44\%) no clinical evidence was observed. Among these, 30 showed articular uptake (in an average of $7.0 * 4.6$ joints). Considering only the patients with clinical evidence, the subjects with articular uptake were 41 out of $42(97.6 \%)$ with an average of $8.6 * 4.6$ involved joints. In these patients the ratio between number of joints with uptake and number of joints with clinical evidence (ratio uptake/clinical) was then calculated for each subject. Such a ratio resulted in an average of $2.9 * 3.6$. These results were also confirmed analysing the data by sex, disease (RA or OA) and class of therapy. We then decided to assess if the greater prevalence of involved joints obtained with bone scan was correlated with an increase of inflammatory indexes. Taking into consideration the patients with clinical evidence, we performed multiple regression analysis using as dependent variable in distinct models the ratio uptake/ clinical, the number of joints with clinical evidence and the number of joints showing uptake. The inflammatory indexes (ESR and CRP) were used as independent variables and age, sex, diagnosis and therapy were used as covariates. The uptake/clinical ratio did not show any significant correlation. The number of joints with clinical evidence correlates with ESR, those ones showing uptake correlates only with age, both with direct correlation.

Conclusion The data obtained indicates that the articular scintigraphic uptake in AR and OA, on average, highlights a significantly higher number of joints involved as compared to the clinical test. It still remains to be defined if this is an overestimation related to the characteristics of the scan or if it is the sign of a higher sensibility in highlighting the inflammation location. An element of caution against the second hypothesis is established by the absence of correlation with the inflammatory indexes.

\section{SAT0213 DETERMINATION OF BONE EROSIONS IN PATIENTS WITH ARTHRITIS BY ULTRASONOGRAPHY, MRI AND CONVENTIONAL RADIOGRAPHY}

${ }^{1} \mathrm{~L}$ Terslev, ${ }^{1} \mathrm{~A}$ Savnik, ${ }^{2} \mathrm{H}$ Christensen, ${ }^{1} \mathrm{E}$ Qvistgaard, ${ }^{3} \mathrm{~S}$ Torp-Pedersen, ${ }^{1} \mathrm{~B}$ DanneskioldSamsoe, ${ }^{1} \mathrm{H}$ Bliddal. ${ }^{1}$ Parker Institute; ${ }^{2}$ Department of Radiology, Frederiksberg Hospital; ${ }^{3}$ Department of Radiology, Gentofte Hospital, Copenhagen, Denmark

\subsection{6/annrheumdis-2001.710}

Background Conventional radiography (CR) is the standard of reference for detection and quantification of destruction in arthritis. However several studies ${ }^{1,2}$ have shown that Magnetic Resonance Imaging (MRI) may be superior to CR in the detection of bone erosion while the use of ultrasonography (US) has not yet been fully clarified.

Objectives To compare CR with US and MRI in detecting bone erosions in patients with arthritis.

Methods 16 patients (9 women and 7 men, median age 50,5 years, range (31-69)) with arthritis were included and examined by CR in 2 planes with Nørgaard views, US with a $15 \mathrm{MHz}$ linear transducer in longitudinal scans consecutively covering the whole joint and by 1,5 T MRI with T1-weighted images. Only wrist, 2nd and 3rd MCP joints were evaluated. A total of 106 bone surfaces in the hands were examined by US ( 45 joints) and 112 bone surfaces by MRI and CR (48 joints). Each imaging modality was evaluated independently. Erosions in CR were 
evaluated on a standardised sheath. An US erosion were defined as a defect in the bone cortex visualised in the longitudinal scan and different from known US bone irregularities due to tendon tracks etc. A MRI erosion was defined as a focal loss of signal intensity within the bone. For all imaging modalities the erosions were marked \pm erosion in the bone surface examined.

Results US detected a total of 36 bone surfaces with erosions, MRI 29 and CR 7. US and MRI agreed on 76 of 106 surfaces (72\%), Kappa $=0,33$; US and CR agreed on 74 of 106 surfaces (70\%), Kappa 0,14 and MRI and CR agreed on 86 of 112 surfaces (77\%), Kappa 0,24.

Conclusion Of the three imaging modalities US and MRI were in closest agreement and both more sensitive than CR. Differences in the US and MRI interpretations of erosions remain to be clarified.

\section{REFERENCES}

1 Klarlund $\mathrm{M}$, et al. Magnetic resonance imaging, radiography and scintigraphy of the finger joints: one year follow up of patients with early arthritis. Ann Rheum Dis 2000;59:521-8

2 Backhaus M, et al. Arthritis of the finger joints. Arthritis Rheum. 1999;42:123245

\section{SAT0214 OS CALCIS DENSITOMETRY (PIXI) FOR OSTEOPOROSIS SCREENING IN POSTMENOPAUSAL WOMEN}

JA Román-Ivorra, L Abad, JJ Alegre-Sancho, C Fernández-Carballido, S Fernández. Sección de Reumatología, Hospital Universitario Dr. Peset, Valencia, Spain

10.1136/annrheumdis-2001.711

\section{Background}

Objectives To determine t-score values which should be applied for the screening of osteoporosis in postmenoapusal women when using a peripheral os calcis densitometer (PIXI).

Methods Heel bone mineral density (BMD) was measured in 81 postmenopausal women with a PIXI densitometer (LUNAR). Results (t-score values) were classified according to the WHO definition and to the manufacturer recommendations (LUNAR): normal >-0,6; osteopenia from $-0,6$ to $-1,6$ and osteoporosis <1,6. Hip BMD measurements (DEXA) were used as to compare the results.

Results Abstract SAT0214 Table 1

\begin{tabular}{llll}
\hline & $\begin{array}{l}\text { Normal } \\
\text { DEXA }\end{array}$ & $\begin{array}{l}\text { Osteopenia } \\
\text { DEXA }\end{array}$ & $\begin{array}{l}\text { Osteoporosis } \\
\text { DEXA }\end{array}$ \\
\hline Normal PIXI(WHO) & 23 & 17 & 2 \\
Osteopenia PIXI (WH0) & 2 & 25 & 6 \\
Osteoporosis PIXI (WH0) & 0 & 2 & 4 \\
Normal PIXI (>-0,6) & 15 & 10 & 0 \\
Osteopenia PIXI (From -1,6 TO - & 9 & 23 & 6 \\
0,6) & & & \\
Osteoporosis PIXI (<-1,6) & 1 & 11 & 6 \\
\hline
\end{tabular}

Conclusion False-negative results for osteoporosis become reduced when $\mathrm{t}$-score classification recommended by the manufacturer are used as cut-off points in heel densitometry. An accurate collection of osteoporosis risk factors can help to identify those patients with hip osteoporosis among patients with heel osteopenia.
SAT0215 DIAGNOSTIC VALUE OF SYNOVIAL FLUID ANALYSIS IN PIGMENTED VILLONODULAR SYNOVITIS (PVS)-A PROPOSAL OF DIAGNOSTIC CRITERIA

I Zimmermann-Górska, M Puszczewicz, G Bia³kowska-Puszczewicz. Rheumatology and Rehabilitation, Karol Marcinkowski University of Medical Sciences, Poznañ, Poland

\subsection{6/annrheumdis-2001.712}

Background PVS is an idiopathic lesion that affects the synovial lining joints, tendons, sheats, and bursea through the production of tumour-like growths. Diagnosis of PVS is difficult. Arthroscopy and biopsy together with microscopic examination is usually a base. According to our experience, cytologic features of synovial fluid is a very useful diagnostic tool in PVS.

Objectives Synovial fluid (SF) from the joints of 14 patients with biopsy-proven PVS were examined. Moreover in all the patients features of the disease were confirmed in surgical specimes.

Methods Synovial fluids were divided into three samples, for physicochemical analysis, bacteriological and cytologic findings and placed in sterile tubes. For cytological examination MMG staining was used.

Results SF analysis had revealed an inflammatory character of effusions. In all the cases synovial fluids were bloody and fragments of synovial villi in their sediments were observed as well as multinucleated giant cells, pseudomalignant cells, macrophages with phagocytized hemosiderin, foam cells an a few synoviocytes. Moreover the fat crystals were seen, under polarised light. Conclusion Cytological features of synovial fluid in PVS are in parallel with results of microscopic examination of joint tissues. In our opinion SF analysis should be the first step in the diagnostic procedure in PVS. We propose the cytologic criteria:

Major

- the presence of bloody fluid with fragments of synovial villi in sediment

- macrophages containing hemosiderin

- pseudomalignant cells

\section{Minor}

- multinucleated giant cells

- foam cells

- fat crystals

The diagnosis of PVS can be establish if all major and at least one minor criteria are fulfilled.

\section{SAT0216 JUXTAARTICULAR AND GENERAL OSTEOPOROSIS IN RHEUMATOID ARTHRITIS - RESULTS OF DXA- DENSITOMETRY}

M Welcker, J Gottwalt, K Wienands, H Franck. Centre of Rheumatology, Waldburg Zeil Kliniken, Oberammergau, Germany

10.1136/annrheumdis-2001.713

Background Juxtaarticular osteoporosis is an early sign of inflammation in conventional radigraphy in Rheumatoid arthritis.

Objectives It should be shown weather juxtaarticular osteoporosis can be analysed by dual x-ray adsorption (DXA) and if there is a correlation to general bone loss in inflammatory joint disease.

Methods 20 patients with Rheumatoid arthritis and 10 patients with Fibromyalgia were analysed by DXA (Hologic 2000). 